\title{
Single Spoke Resonators: String Assembly and Mechanical Design
}

FERMILAB-POSTER-20-023-TD

SSR1 Cavity String Assembly
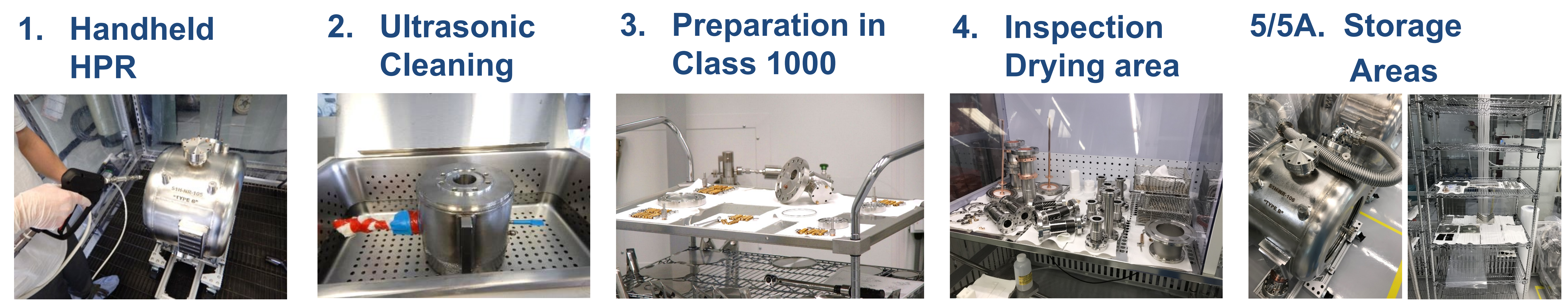

6. Dry Cleaning Area
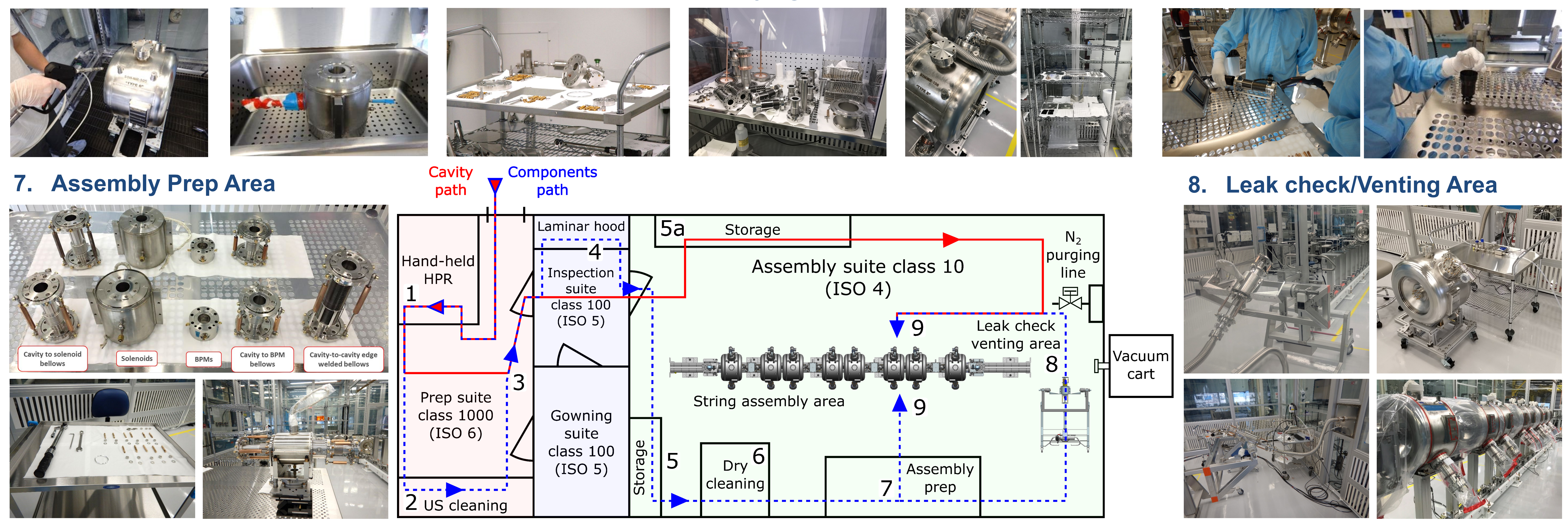

\section{Leak check/Venting Area}

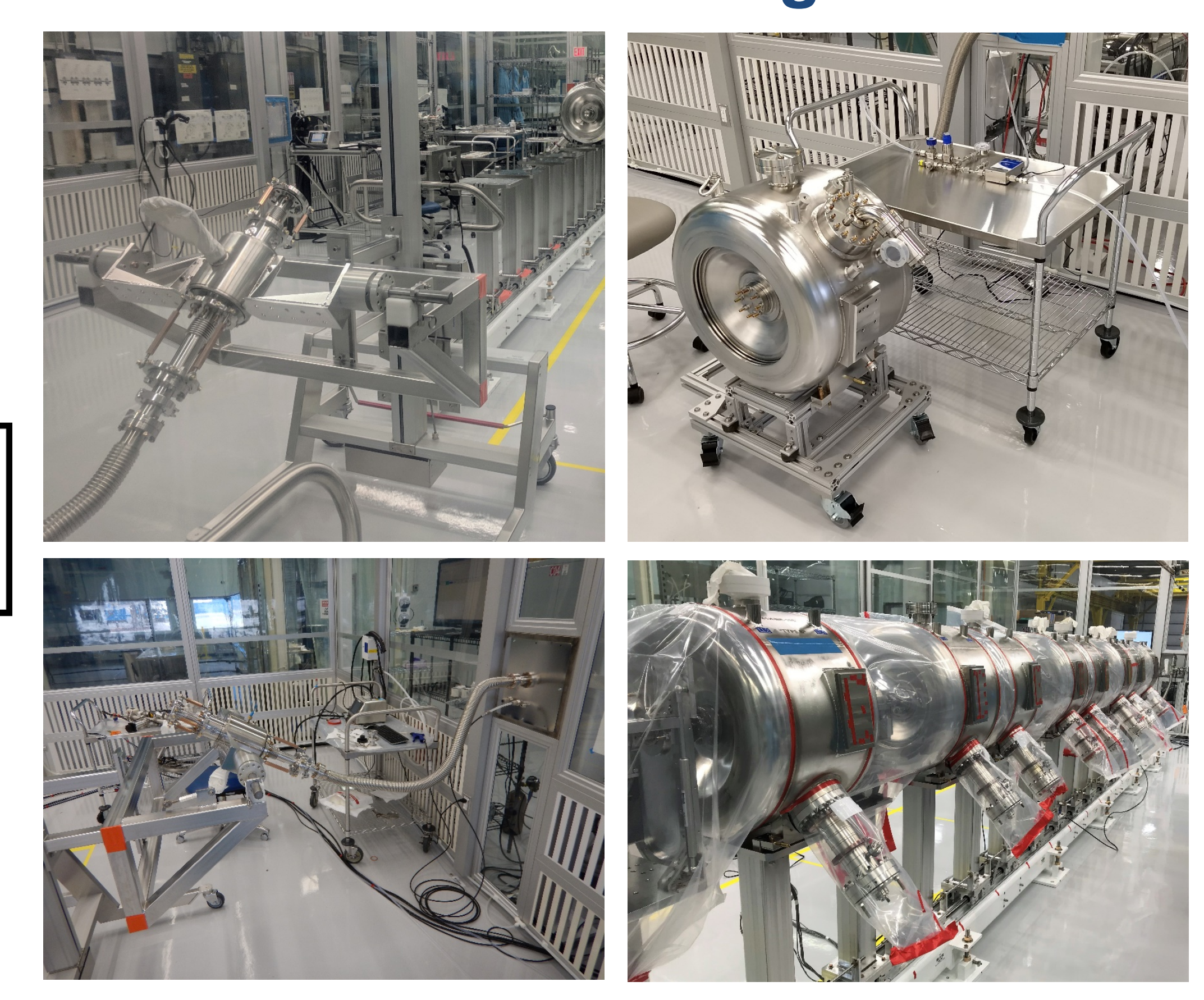

9. Final Assembly
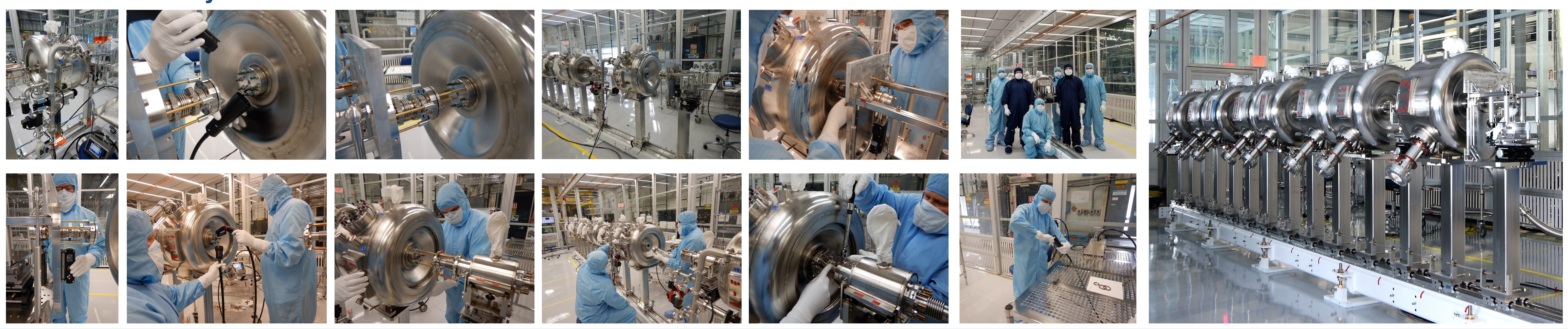

SSR2 Jacketed Cavity Mechanical Design

SSR2 Bare Cavity

Bellows Side

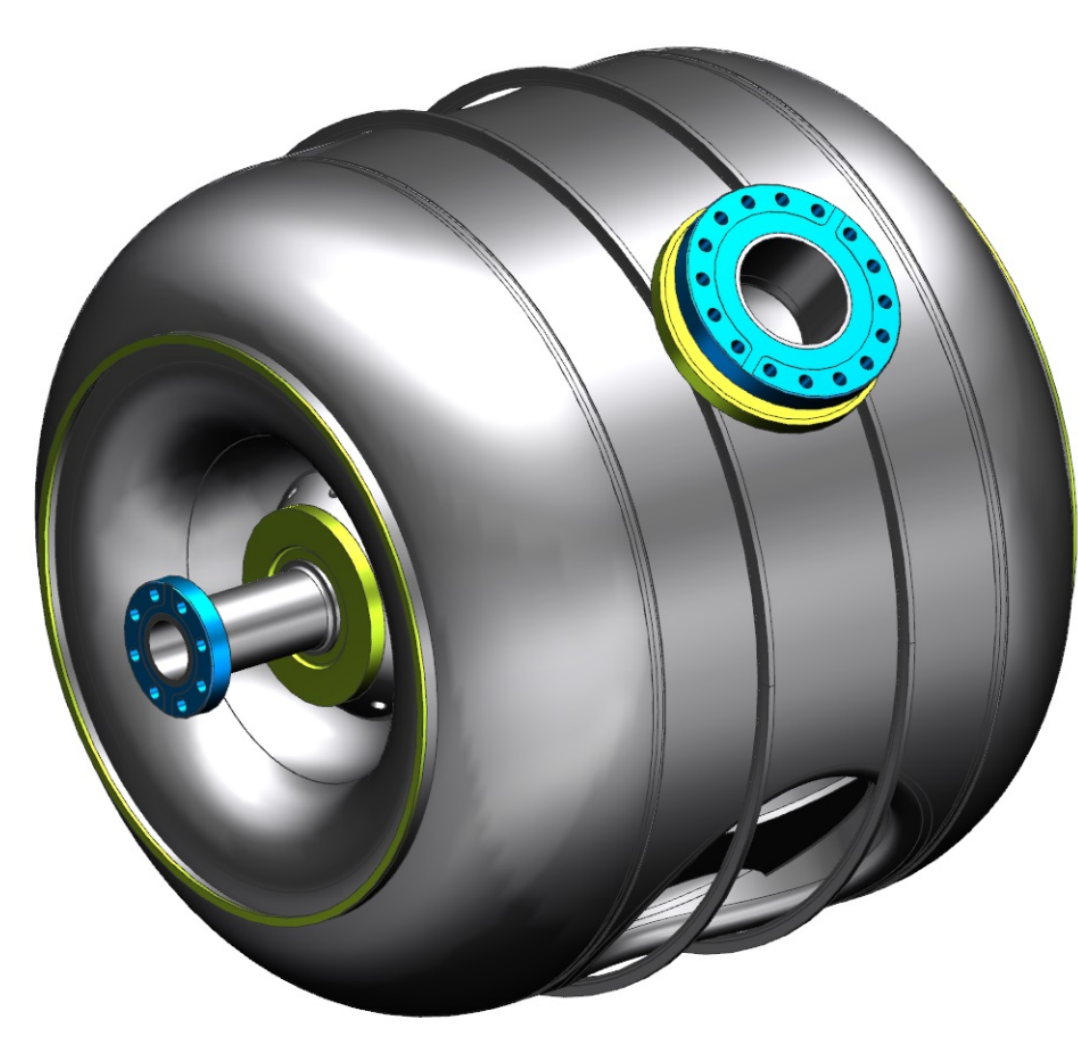

Ring Side

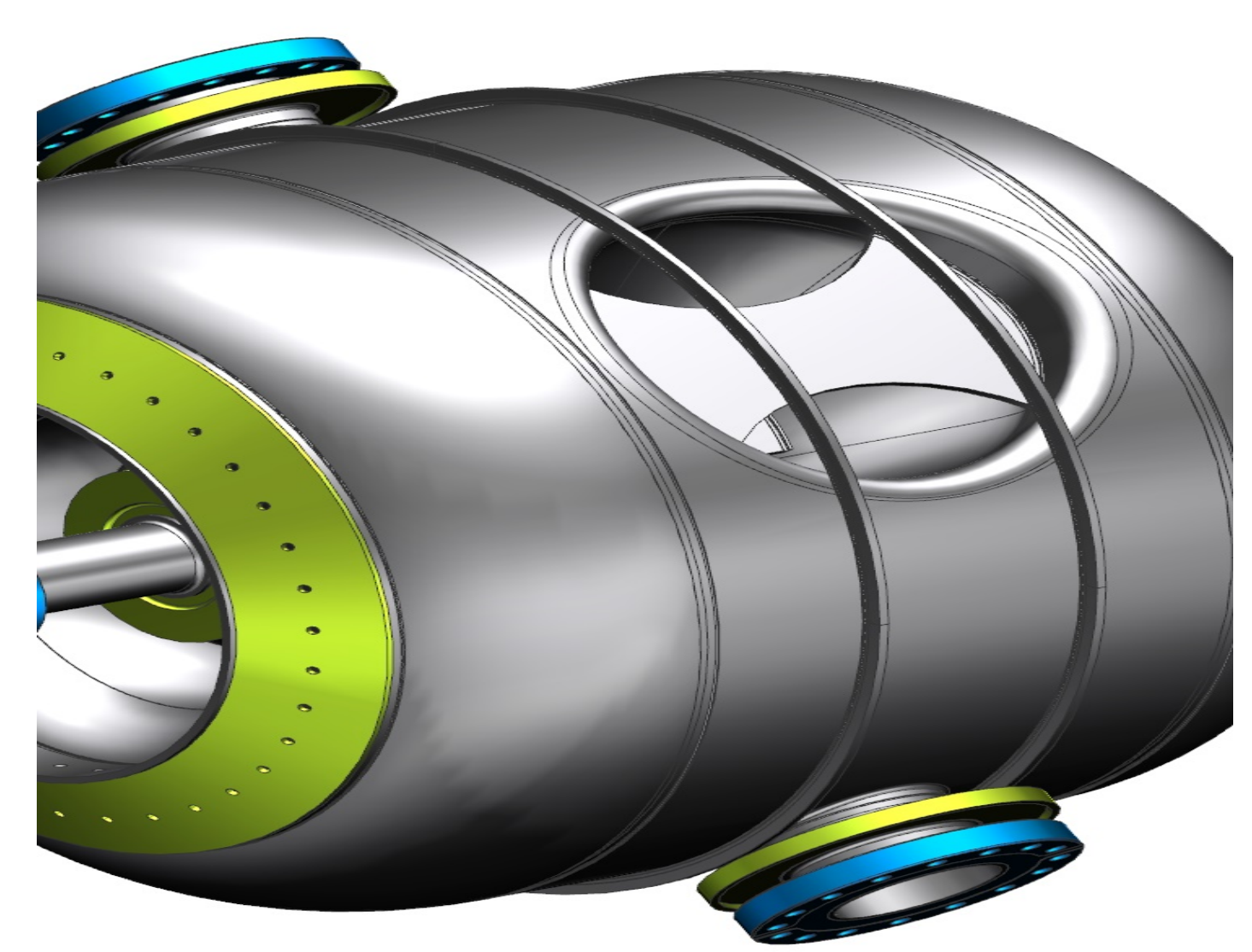

Side port tube $\mathrm{x} 2$
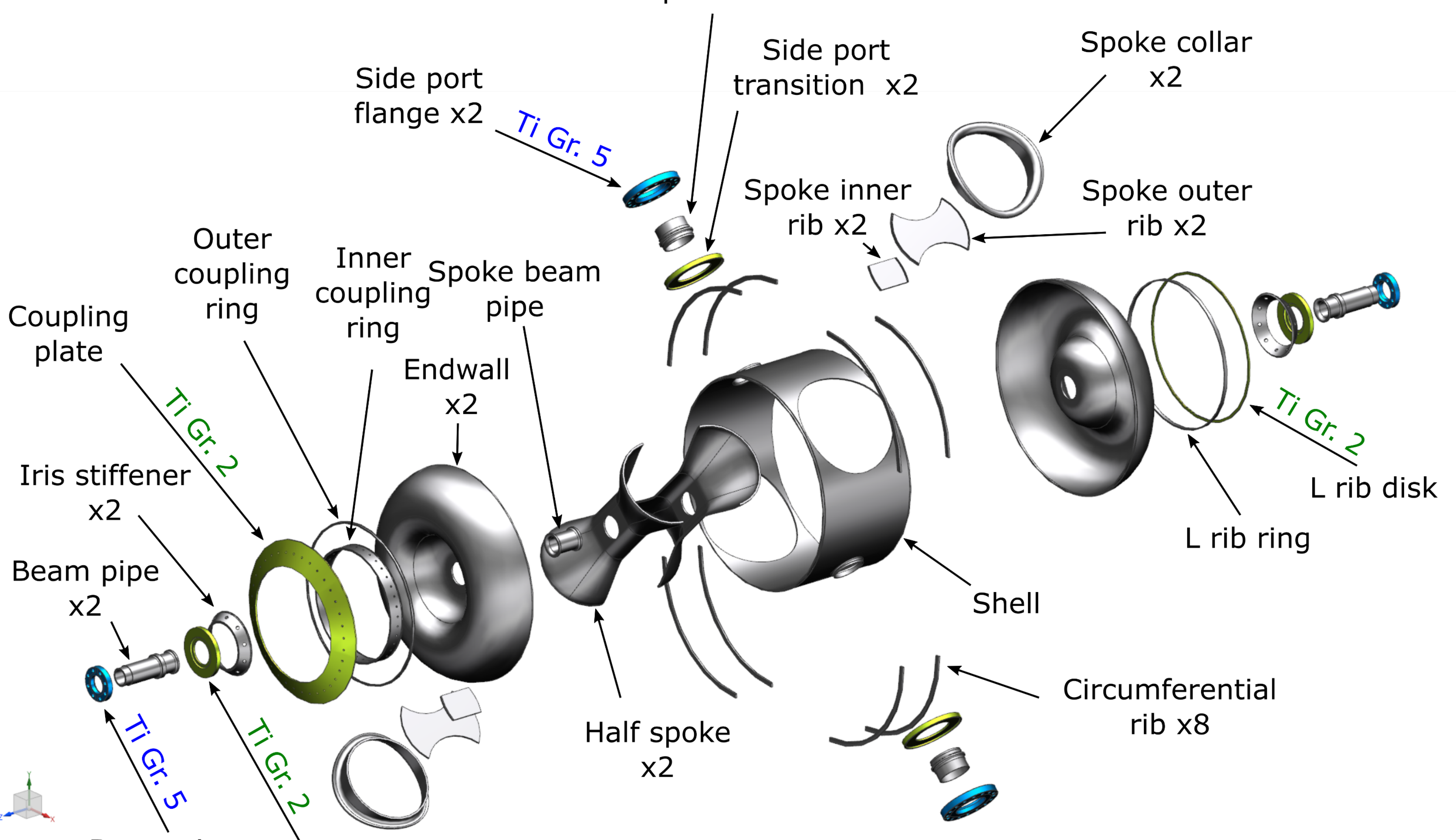

Beam pipe
flange $x 2$ Beam pipe

SSR2 Jacketed Cavity

Bellows Side

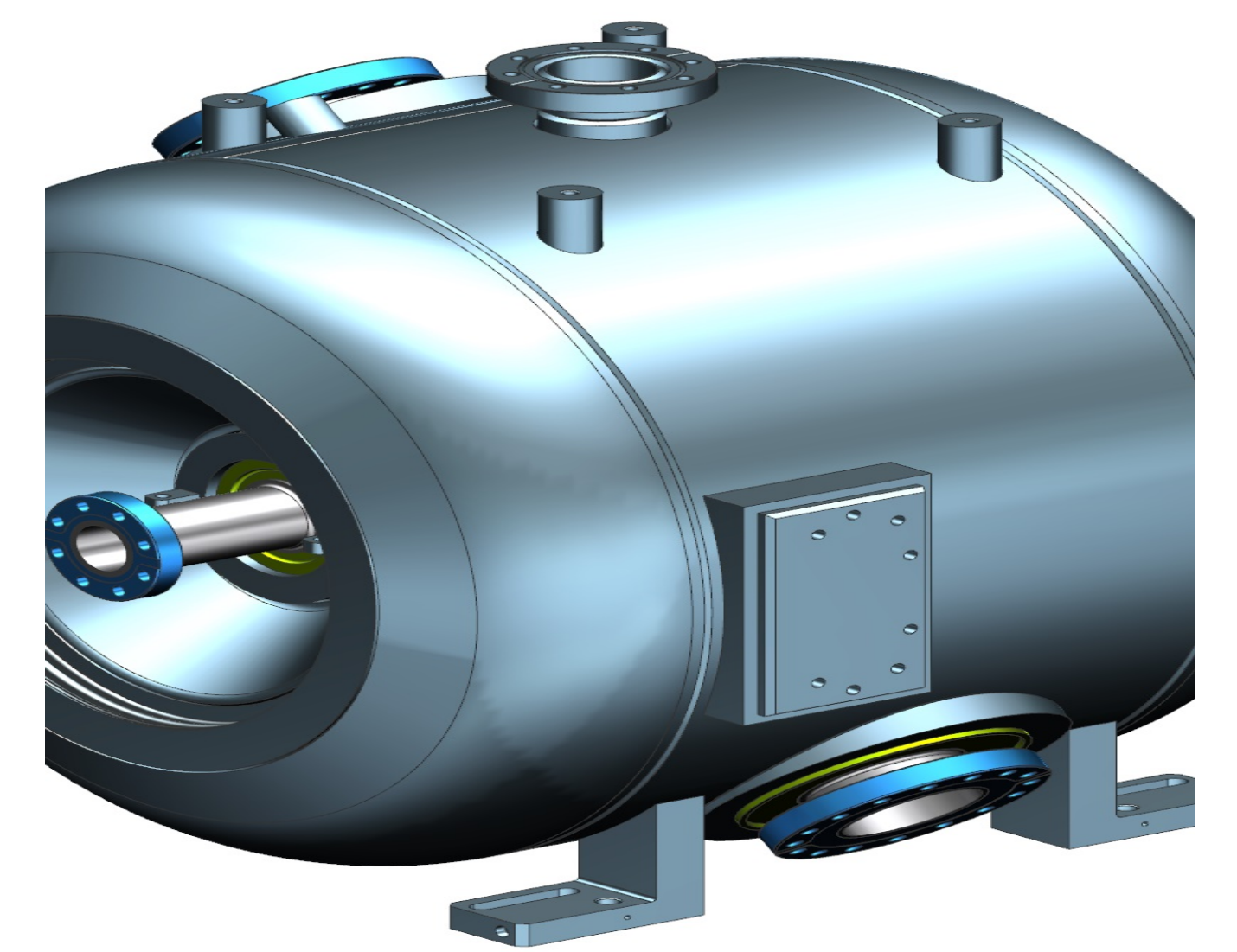

Ring Side

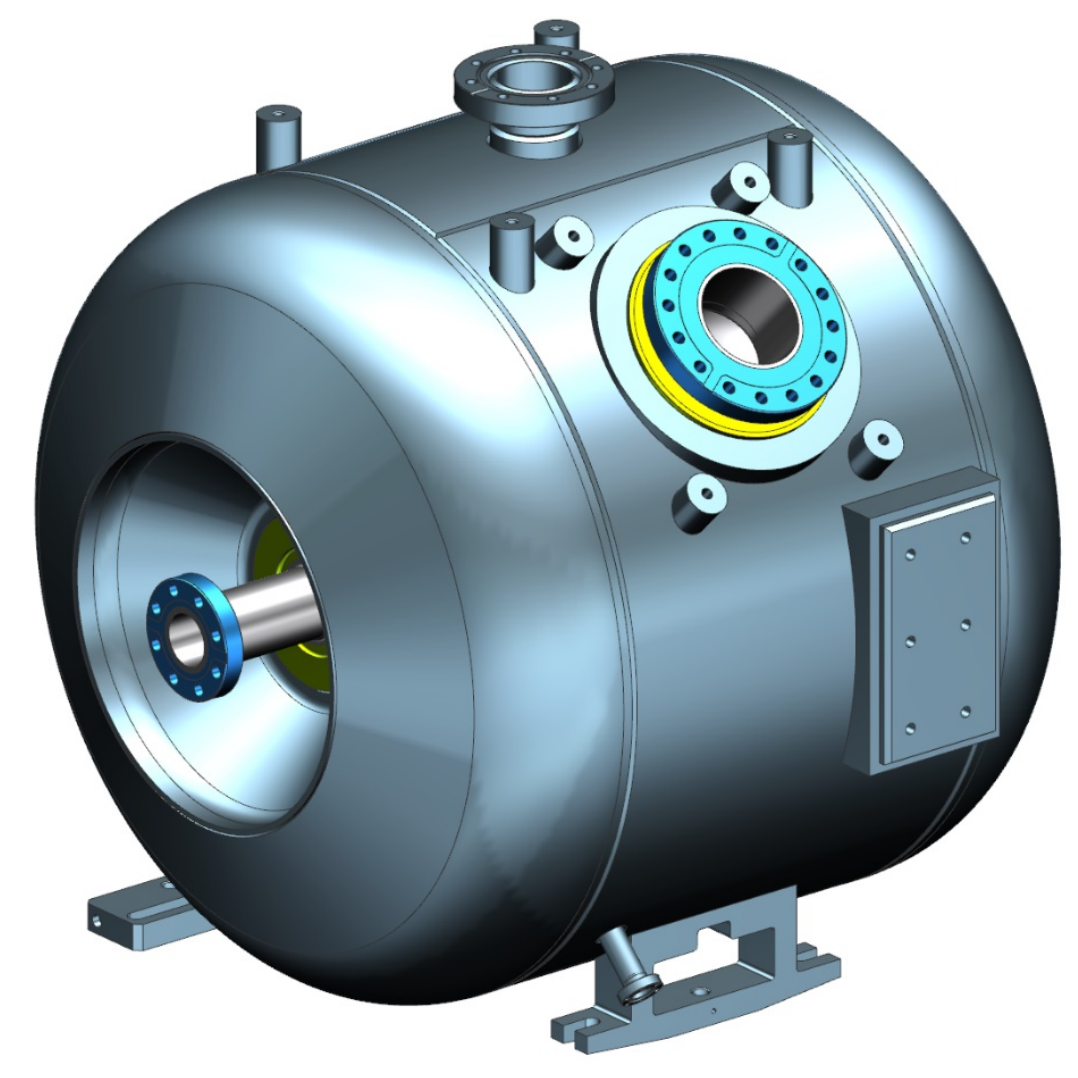

Two-phase

Two-phase flange
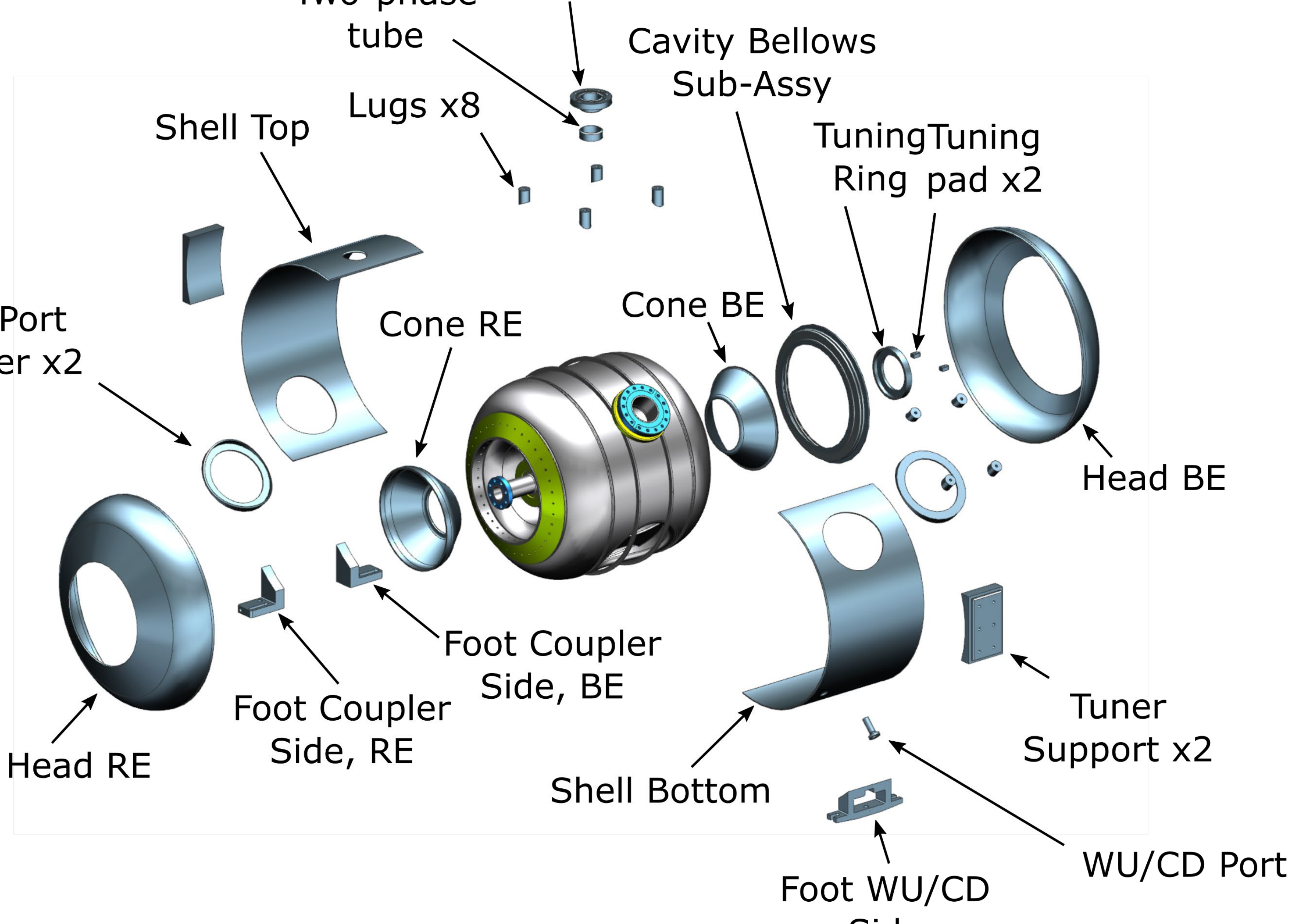

Side Port
This manuscript has been authored by Alliance, under Contract No. DE-AC0207CH11359 with Department of Energy, Office of Science, Office of High Energy Physics. 